\title{
Nineteenth century exercise clinics for the treatment of scoliosis
}

\author{
'S Elsaesser, ${ }^{2} \mathrm{AR}$ Butler \\ ${ }^{1}$ Clinical Student, Medical School, University of Manchester; ${ }^{2}$ Honorary Professor, Bute Medical School, University of St Andrews, UK
}

\begin{abstract}
Scoliosis is the abnormal lateral curvature and rotation of the spine. In the past this deformity has been linked with moral depravity, as in the case of Richard III. Treatment for scoliosis began with Hippocrates's use of boards and axial distortion. Today, bracing and surgery are used either to correct the deformity or to prevent further progression. In the past, however, exercise regimens have been used in the belief that strengthening back muscles would reduce curvature progression. This approach was pioneered by Per Henrik Ling in the early nineteenth century and was continued by his followers Mathius Roth and Franz Berwald and, most notably, by Gustav Zander. Even today a few clinics, particularly in Eastern Europe, still use exercise in the treatment of scoliosis. Whether it is effective remains debatable, but even if progression is not prevented the patient's general health will benefit from an exercise regimen.
\end{abstract}

Correspondence to AR Butler Purdie Building

University of St Andrews St Andrews KYI6 9ST

UK

e-mail arb3@st-andrews.ac.uk

KEYWORDS exercise, scoliosis, spinal curvature

DECLARATION OF INTERESTS No conflict of interests declared.

\section{INTRODUCTION}

In 2012 a skeleton was unearthed from beneath a council car park in the English city of Leicester.' Part of the evidence that this is the skeleton of the English king Richard III (1452-85) was its curvature of the spine, for Richard was known as the hunchback monarch. Shakespeare rather laboured on the deformities of Richard and called him a 'pois'nous bunch-back'd toad'2 in order to emphasise his moral depravity. From the few portraits we have of Richard III, the deformity appears so slight that it was diagnosed as mild Sprengel's deformity. ${ }^{3}$ The recently discovered skeleton indicates he was afflicted with a relatively common condition that has nothing to do with moral depravity: a form of spinal curvature known as scoliosis. He was not the only royal personage to display skeletal evidence of scoliosis. A similar deformity was noted when the remains of Princess Anna Vasa (1568-1625), sister and advisor to King Sigismund III of Poland, were discovered during a church restoration in 1994. ${ }^{4}$ In spite of great advances in its surgical treatment, scoliosis remains a distressing condition mainly for its psychological impact as its disabling effects may be minor.

\section{HISTORY OF SCOLIOSIS}

Hippocrates (460-377BC) was the first to describe abnormal spinal curvature in the Western medical literature; he coined the term 'scoliosis' (skolios is Greek for 'bent') and thought the condition was due to poor posture. His recommended treatment was axial distraction on an extension apparatus known as a
Hippocratic board. ${ }^{5}$ Claudius Galen (I3I-20|AD) refined Hippocrates's account and distinguished three types of spinal deformity: scoliosis, kyphosis and lordosis. ${ }^{6}$ $\mathrm{He}$ recommended additional remedial procedures, including loud singing, arguing that exercise of the rib cage might correct some of the thoracic distortion.

The prevailing attitude towards deformity in ancient societies varied. In ancient Egypt deformity was accepted and nobles had dwarfs and other misshapen people in their household retinues. In some instances, deformity was seen as a mark of divinity. ${ }^{7}$ In contrast, in ancient Greece the admiration for physical perfection, seen so readily in Greek statuary, meant that those with deformed bodies were rejected. Aristotle even went as far as proposing a law to prevent parents from rearing deformed children. ${ }^{8}$ Deformed slaves were often kept as a rather barbaric form of entertainment for guests, a custom retained by the Romans. ${ }^{9}$

However, it was during the mediaeval period that life was particularly bad for deformed people. The notion linking deformity with sinfulness, already present to some extent in Graeco-Roman society, flourished under the mediaeval church. Physical affliction was seen as a reflection of the moral depravity of the soul. Often the sin being punished was merely an infringement of church law. For example, deformed children could be conceived as a result of a woman not abstaining from sexual intercourse prior to churching after childbirth. ${ }^{10}$ Beggars were often deformed people who, although rejected 
socially, might still receive charitable alms. Throughout the mediaeval period little thought was given to the possibility of rectifying deformity by medical means. With the Renaissance, a more humane attitude emerged and increasing attention was given to the treatment of, among other conditions, spinal curvature

\section{SCOLIOSIS TODAY}

The precise definition of scoliosis is lateral curvature and rotation of the spine in the coronal plane, often resulting in an unsightly dorsal prominence of the ribs on one side (Figure I). It is a progressive condition. Although it may be the result of a number of disorders, such as congenital anomalies of the vertebrae or major neuromuscular diseases, most cases (65\%) are idiopathic in nature and occur in otherwise healthy children. This type commonly becomes noticeable between the ages of 9 and 14, affecting girls five times more often than boys. Today, if the curvature is unacceptable, surgery is recommended. Steel rods or other implants are used to correct the deformity and the affected segments of the spine are fused. The success of this operation can be judged from the fact that the winner of 2013 British Women's Open Golf Championship, Stacey Williams, had the operation while at high school. If the curvature at presentation is acceptable then prevention of further progression is the aim." Over the decades a number of treatments to prevent progression have been proposed, including bracing, traction and, most controversially, remedial exercises. The last of these was the treatment most widely available in the past.

\section{EXERCISE AS THERAPY}

In Western civilisation the Greeks, more than any other culture, had a passion for exercise, particularly athletics. Olympic Games are recorded from as early as 776BC. Young men were instructed in exercise, bathing, massage, gymnastics and diet. The situation is described by Porter:

Throughout Greek civilisation, as with Roman later, ideals of manliness required one's physique in peak condition; admiration of the lithe, fit, attractive warrior shines through classical art and myths. Dancing, martial arts and working out in the gymnasium with the help of trainers - men-only practices, women being excluded from public life - were regarded as essential for the well-being of the body. ${ }^{12}$

This view is encapsulated in Juvenal's well-known epigram mens sana in corpore sano ('a sound mind in a healthy body'). However, much of this attitude was lost during the medieval period in Europe as sport was largely limited to hunting which, although providing physical activity, does not provide the same focus as that

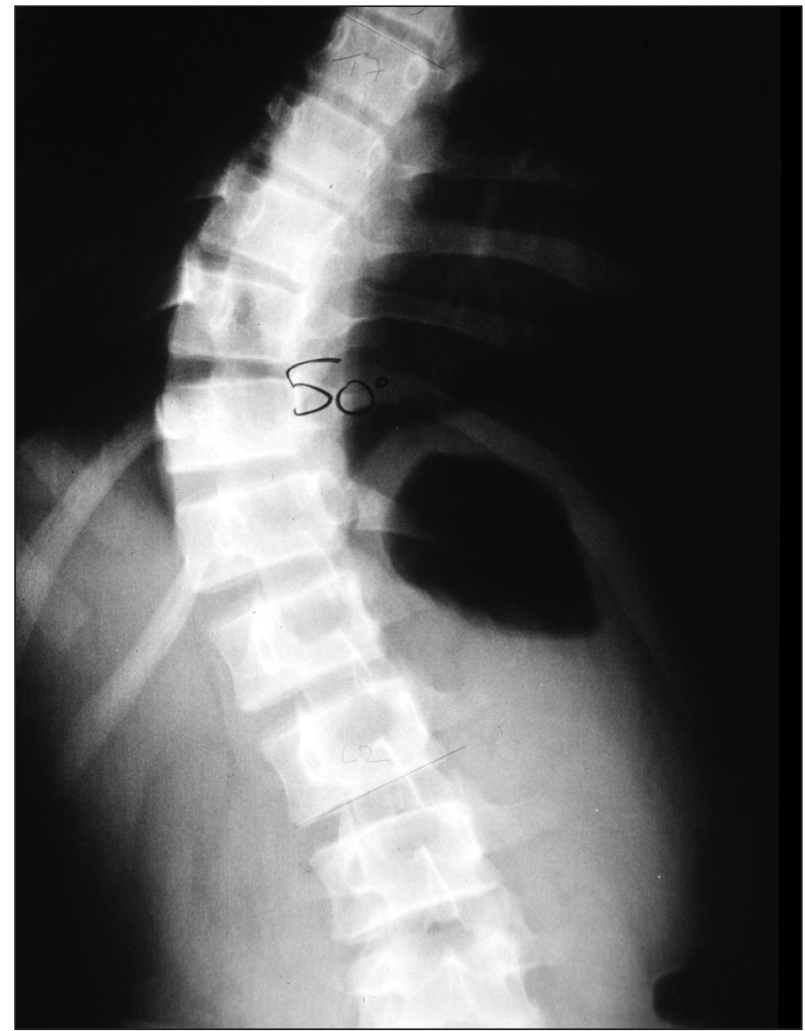

FIGURE I A radiograph showing an idiopathic thoracolumbar scoliosis in an adolescent girl. Image supplied by Mr Geoffrey Hooper

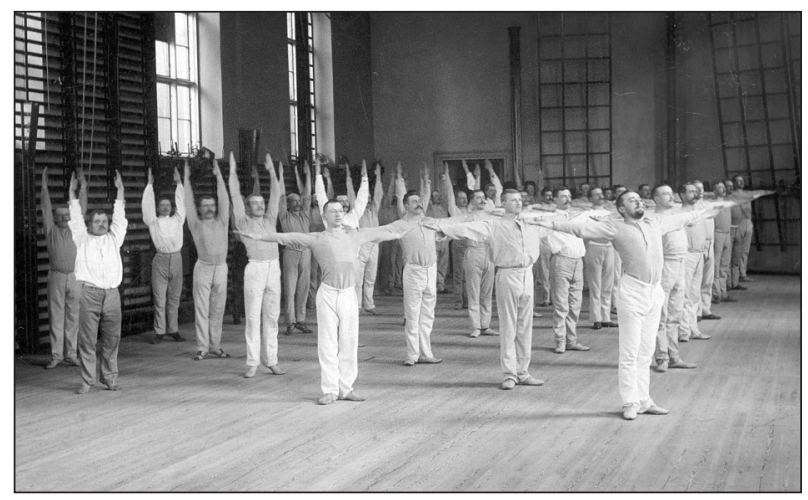

FIGURE 2 An exercise class at Ling's Institute in Stockholm (Gymnastik och Indrottshögskolan, Stockholm)

practised by the Greeks, and was available only to the wealthy. As modern medicine began to emerge so too did an interest in sport and various forms of exercise.

\section{LING'S SWEDISH EXERCISES}

The word 'orthopedia' (literally 'straight child') was chosen by Nicholas Andrél3 for the title of his 174I treatise in which he emphasised his belief that scoliosis was the result of muscle imbalance. From this it is therefore not unreasonable to deduce that the strengthening of certain muscles, weakened by bad 


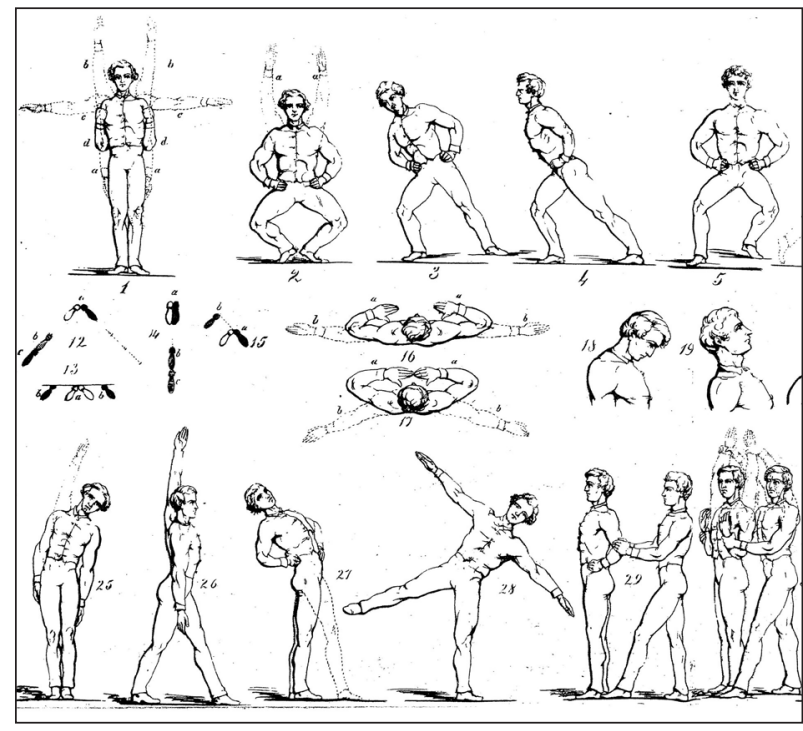

FIGURE 3 A diagrammatic representation of exercises used in Roth's London clinic

posture, could slow down the progression of spinal curvature, if not stop it altogether.

Among the first to develop an exercise programme that had a remedial aspect was the Swedish fencing master Per Henrik Ling (1776-1839). Born in Småland of a longlived family (his grandfather lived to 104 and his grandmother to 103), his early life is something of a mystery, but we know he learnt fencing at the University of Copenhagen. At this time he also became fascinated by the old Viking sagas and obsessed by the idea of physical prowess as emblematic of manhood (his own Nordic sagas have, mercifully, been lost for he showed no talents as an author).

His first paid employment was as fencing master at the University of Lund, where he introduced swimming, climbing, wrestling, balance exercises and other forms of gymnastics. He studied anatomy and concluded that exercise could cure some anatomical defects. His idea was that gymnastics could reshape the body; lunging and stretching exercises were developed for this purpose. Around 1813 he opened a gymnastic training school in Stockholm, the Kungl. Gymnastiska Centralinstitutet (Royal Central Institute of Gymnastics), to give expression to his ideas. It was a great success. ${ }^{14}$

Ling wrote little about his methods, but one of his British disciples, Mathius Roth, has given us a full account of Ling's system. ${ }^{15}$ The exercises were done in unison, rather like a modern aerobics class. Figure 2, photographed in Ling's Centralinstitutet around 1900, gives an idea of what one of Ling's classes was like. However, a Swedish-language manual published in the 1930s does suggest that pieces of gymnastic apparatus were introduced at some stage. ${ }^{16}$
The British physiologist Marcus Pembrey was very critical of Ling's procedures on the grounds that the feet were set in a very unnatural angle, breathing was regulated rather than spontaneous and, as the exercises were done in unison, no allowance was made for different levels of fitness. ${ }^{17}$ In Sweden, Ling's institute metamorphosed into hospital physiotherapy departments, but 'Swedish exercises' were practised by individuals throughout the twentieth century as a means of maintaining physical fitness.

\section{ROTH'S LONDON CLINIC}

Mathius (or Bernard) Roth (1818-57) was Hungarian by birth and studied medicine in Vienna and Padua. He returned to Hungary to participate in the War of Independence in 1849 and, as a result of its failure, fled the country. He settled in London and eventually became a physician in the Hahnemann Hospital. Roth attended gymnastic classes run by one of Ling's disciples, Carl August Georgii, and became so enthralled by the technique that, in 1857, he started his own classes at a centre in Cavendish Street and the classes flourished. He included women and founded the Ladies Sanitary Association. An example from Roth's exercise regimen is shown in Figure 3.

Did Ling and Roth promise to do more than improve the general physical fitness of those who attended their classes? Was there any attempt to correct deformities? Ling left so few records that it is difficult to say, but there is an image in an article by a Swedish physiotherapist on Ling and his methods ${ }^{18}$ showing three attendants manipulating the body of a patient and the caption reads 'treatment of scoliosis'. Since labour was cheap three attendants for one patient was not exceptional. There is no elucidation in the text of what the treatment was and the source of the image is given merely as 'from a contemporary illustration'. Despite the lack of detail, this image does suggest that Ling promised correction as well as fitness.

However, it is difficult to see how this could have been achieved by his communal exercise regimen. If, as was generally believed, spinal curvature was caused by muscle imbalance, with one set of muscles stronger than its opposite number, then the exercise would have to be asymmetrical in order to strengthen the weaker set. What Ling had to offer for the treatment of scoliosis, as suggested in the illustration, is something of a mystery.

Roth was much more explicit in his aims and in his book claims that exercise would not only 'empty the workhouses and restore the health of young men' but also correct deformities. He also wrote a pamphlet entitled Treatment of Lateral Curvature of the Spine ${ }^{19}$ and 


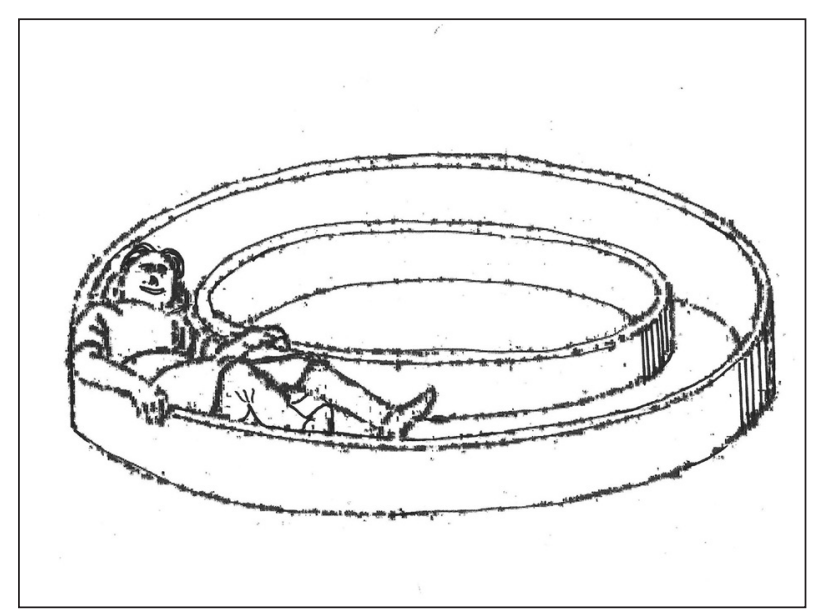

FIGURE 4 Example of Berwald's apparatus for the treatment of scoliosis (taken from a pencil drawing of 184I in Kungl. Musikaliska Akademien, Stockholm, kindly supplied by Margareta Rörby)

was in no doubt that some deformities could be corrected by exercises in the Ling style. In a letter to the Lancet, $^{20}$ Roth deplored the use of steel and other supports for the treatment of deformed shoulders in young girls. He wrote: 'Such patients require the muscles of their scapulas and spine to be strengthened by suitable and systematically applied exercises (medical gymnastics, Swedish exercises, etc)...'20

Roth then asserts his success in the use of such procedures. He gives no solid evidence of this promised success and exactly what he achieved is difficult to assess but, as he did devise asymmetric exercises, his regimen is an improvement to that of Ling as a remedial procedure. He took scoliosis seriously for he invented a device for measuring spinal curvature (a lead strip that could be moulded along the spine and then recorded on paper by tracing). Towards the end of his professional life, he became more interested in legislative and political matters related to physical education and the remedial aspects of his exercise regimen were not pursued. His plea for the teaching of physical education in state schools was eventually accepted and included in the I870 Education Bill.

\section{BERWALD'S BERLIN CLINIC}

Another disciple of Ling who focused on the treatment of spinal deformity was the Swedish musician Franz Berwald (1796-1868). He was a violinist and an aspiring composer, but his musical career in Stockholm did not achieve the success he had hoped for and he moved to Berlin, where once more musical success eluded him. In 1835, to make a living, he established an orthopaedic clinic for the treatment of scoliosis among young girls, using as the basis of his therapy what he had learnt from Ling.
Berwald's patients were resident and his wife cared for them in what appears to have been a humane household. From the start, unlike Ling and Roth, Berwald designed and used pieces of apparatus to assist in correcting deformity. When he sold the clinic in 1844 he made drawings of the equipment, with dimensions, and these drawings have survived. One is shown in Figure 4; the female figure is probably his long-suffering wife Mathilde.

It looks a little harsh, but Berwald claimed considerable success from his programme. Among other authorities, he was inspected by the Berlin police and his work was praised; whether the police had the relevant expertise is questionable. More significant praise came from physicians attached to the Karolinska Hospital in Stockholm who visited him to examine his methods and considered that he obtained positive outcomes. Although Berwald's clinic was short-lived, he did pioneer gymnastic apparatus for the treatment of scoliosis, which may have influenced later practitioners. Berwald relocated to Stockholm where his musical life revived and today his music is occasionally played, particularly in Scandinavia. ${ }^{21}$

\section{OTHER PRACTITIONERS}

Throughout the nineteenth and early twentieth centuries, a number of practitioners attempted to ameliorate the effect of scoliosis by physical means. Noble Smith, an Edinburgh graduate and surgeon at the Orthopaedic Hospital in London, proposed in 1900 an exercise regimen for patients with spinal deformity: 'My present purpose is to consider the local effects which may be produced upon a crooked spine by specified muscular exercises, either by correcting the shape of and strengthening the joints, or by strengthening any particular set of muscles connected to the deformity. ${ }^{22}$

Although there is plenty of detail concerning ways of assessing the patient to see whether the procedure is appropriate, Smith provides few details and no evidence that the procedure was successful. His work seems to have been quickly forgotten. There is a very useful manual published in 1897 by Percy Lewis, a general practitioner in Folkestone ${ }^{23}$ describing sets of exercises, both symmetrical and asymmetrical, for home use by those with spinal curvature. The first set improves the general muscle tone of the body, something of value to the patient, and the second tackles directly the muscular shortcoming responsible for the curvature. Lewis provides little evidence of his successes, but his treatment of symmetric and asymmetric exercises is perceptive.

Edward Harrison (1759-1835) is most famous for founding a public dispensary in Horncastle, Lincolnshire, ${ }^{24}$ but in 1820 moved to London to establish a clinic specifically designed for the treatment of spinal deformity. His technique appears to a have been a manipulation of 


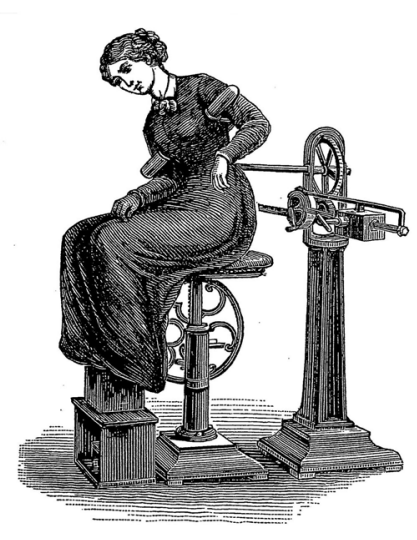

FIGURE 5 Machine used in a Zander clinic for the treatment of scoliosis

bones, particularly the spine.According to his biographer, many of Harrison's cases were published in the London Medical and Physical Journal, but the medical establishment was unimpressed and he became a controversial figure. Exactly what he did is difficult to discern, ${ }^{25}$ but it appears to have been a form of chiropractic before it was established as a recognised alternative by Daniel David Palmer in 1895. The validity of chiropractic successes are controversial to this day and Harrison's claims are difficult to believe. He appears to have used remedial exercises to only a minor extent in his treatment and so his work is tangential to this account.

\section{GUSTAV ZANDER}

One of the most serious and successful exponents of remedial exercises in the pursuit of health and the treatment of a number of defects was yet another Swede, Gustav Zander (1835-1920). From his earliest days in Stockholm he practised gymnastics in the Ling tradition. Even before he went to medical school Zander saw that the benefits of gymnastics were available only to those fit enough to stand the strain of vigorous exercise. He later wrote: 'Ladies, young girls, elderly men, and weakly persons of either sex are almost entirely excluded ...26 To provide exercises of benefit to the weak, ladies and those recovering from illness, he devised a number of mechanical devices where a system of levers provided resistance matching the strength of the patient. He tried out his machines on children in a local school and judged the results so good that, around 1865, he set up his Medico-Mechanical Institute in Stockholm with 27 such machines. It was an immediate success, although scorned by the medical establishment. Over the years similar clinics were set up all over Europe, North America and elsewhere. The London clinic was established in 1882 in Soho Square and contained 33 machines worked by the patient and 19 worked by an engine to provide passive exercise. Figure 5 shows a typical Zander machine and similar pieces of apparatus are found in fitness suites today. At the movement's peak in 1911, there were 202 clinics worldwide, but the death of Zander, the world wars and changing social habits eventually closed all the clinics.

Great claims were made by Zander and his staff for the value of using the apparatus in the pursuit of general health but also in the treatment of rheumatism, lumbago, sciatica, stiff joints, constipation and, most significantly, curvature of the spine. The clinics tended to take on a character according to the country in which they had been established. Those in North America became gymnasia, catering for the needs of an affluent middle class who led stressful, sedentary lives, while clinics in European spa towns (such as Opatija in Croatia ${ }^{27}$ ) concentrated more on the therapeutic activities, particularly rehabilitation after surgery. This aspect of the clinic was encouraged by states where government insurance schemes had been introduced since a rapid return to work saved taxpayer's money and led to a streamlining of exercise regimens in Zander clinics. ${ }^{28}$

However, the treatment of spinal deformity was not completely phased out. The apparatus shown in Figure 5 was considered particularly useful in this regard. The use of the machine is given as follows: 'The patient first raises herself from the crooked position, afterwards bends herself from the upright position to the opposite side, then resumes the original position. ${ }^{26}$ Other machines were said to complement the above exercise.

\section{EFFICACY OF EXERCISE}

Testimonies of success for all the clinics described are largely anecdotal and, by modern standards, flawed. However, it should be remembered that 'controlled trials' (that is, trials in which there is a control group) are a relatively recent innovation from the 1950s. Until then a new treatment was recommended or adopted either because it was miraculous, like the advent of penicillin, or because it was loudly promoted by a prominent member of the medical profession or the establishment practising it, accompanied by glowing testimonials from grateful patients.

In assessing a treatment for scoliosis there are special difficulties. It would be unethical to take, say, a group of young girls with early signs of scoliosis and put them through an exercise regimen and then compare them with a similar group that had not been treated. Also the progression of spinal curvature is so difficult to predict and can sometimes remain slight without any treatment that lack of progression cannot be credited to a particular therapy with any degree of assurance. It is frequently assumed that therapy can be discontinued once general skeletal growth has ceased at about age 16, but the spine continues to grow minimally until the age of 25 , making complete monitoring a protracted matter and probably 
compliance could not be maintained for the whole period." However, in spite of the weak evidence, the view that exercise can correct scoliosis has not died out. In bookshops, in the alternative medicine section, there will be books such as that by Kevin Lau on 'natural scoliosis prevention', ${ }^{29}$ which asserts that exercise, coupled with an appropriate diet, can prevent the progression of spinal curvature. There are also a number of clinics, based mainly in eastern Europe, that treat scoliosis by a physical regimen, including, as a major component, remedial exercises. As there is now a much greater understanding of human anatomy, modern clinics have a rationale consistent with that increased knowledge. Some of the regimens include the use of braces as well as exercise. The main ones are briefly described below:

- Side shift therapy, developed by Jwalant Mehta, consists of a series of exercises in which the patient shifts the trunk in the opposite direction to the convex part of the spinal curvature. ${ }^{30}$

- Scoliosis in-patient rehabilitation, developed by Kathrina Schroth, is an exercise system that facilitates correction of the asymmetric posture and maintains it in daily life. ${ }^{31}$

- The Dobosiewicz Method, developed by Krystyna Dobosiewicz, attempts to displace the thoracic vertebrae back to their correct position in stages by physiotherapy, mobilisation and kinematic chains and girdles. $^{32}$

- The Scientific Exercise Approach to Scoliosis (SEAS) developed by Stefano Negrini, aims to activate the reflex motor neurones that correct posture and then render it stable. ${ }^{33}$

These regimens appear, for the most part, to be upgraded and more sophisticated versions of the procedures used by older practitioners. They have all been subjected to analyses of outcome by review procedures and have come out with a positive rating. However, 20 of the most acceptable of these reviews were assembled for a Cochrane review and 18 were rejected. ${ }^{34}$ The reasons were given as poor assessment of curvature (which nowadays requires costly X-ray and other scanning equipment), too few patients, too short a follow-up time, no control of compliance and no control group for comparison. The original reviews were generally undertaken by the clinic promoting a particular exercise regimen and some measure of author bias is almost inevitable. The remaining two reviews did give positive results for the value of exercise in the prevention of scoliosis progression, but the effects were too small to be of real clinical value.

So we reluctantly conclude from these contemporary studies that many of the claims of Ling, Roth, Berwald, Zander and others were unfounded. The US National Institutes of Health's pamphlet on scoliosis, published in 2012, certainly comes out firmly against exercise as a viable treatment for scoliosis. ${ }^{35}$

\section{CONCLUSION}

In view of what appears to be their lack of success, it might be surprising that exercise clinics flourished in the way they did. However, unlike Mesmer's magnetic treatment, they were not based on nonsense, for the close connection between bones and muscle suggests that the strengthening of one might have an influence on the other and provides a rationale for exercise as a means of preventing the progression of scoliosis. Yet it appears, in the light of current evidence, that it does not work, despite the sensible rationale. In the absence of any alternative it is not altogether surprising that sufferers clung to the belief that their exercise regimen would have benefits.

Remedial exercise is an alternative therapy that is bound to be beneficial to the sufferer, even if it does not do exactly what it claims. Those running exercise clinics were not exploiting the gullibility of the public, but providing some hope for those whose future was bleak because of the general prejudice against deformity. As mild scoliosis does not normally cause the sufferer pain, the most significant harm it does is to the sufferer's selfesteem and sense of self-worth. That someone, by advising them on an exercise regimen, was trying to help them and probably providing a certain amount of counselling, may have done something to mitigate the adverse psychological impact of spinal curvature.

\section{REFERENCES}

I Knight S, Lund MA. Richard Crookback. Times Literary Supplement 6 February 2013. http://www.the-tls.co.uk/tls/public/ article I208757.ece

2 Shakespeare W. The Tragedy of Richard III, Act I, Scene 3, line 246.

3 Rhodes P. Physical deformity of Richard III. Br Med J 1977: 2: 1650-2.

4 During E. [Princess Anna Vasa - her fascinating life story and skeleton]. Sven Med Tidskr 2005; 9: 9-25. (Swedish)

5 Withington ET. Hippocrates on joints 47 (Loeb Vol. 3). London: William Heinemann; 1928. p. 297-9.

6 Galen. Commentary on articulations. Vol. I8. Leipzig: Kühn. p. 493-4.

7 Dawson WR. Pygmies and dwarfs in ancient Egypt. J Egypt Arch 1938; 24: 185-9.

8 Aristotle. Politics Book VII.Transl Kraut R. Oxford: Clarendon Press; 1998. p. 19-24.

9 Sullivan R. Deformity - a modern Western prejudice with ancient origins. Proc R Coll Physicians Edinb 2001: 31: 262-4.

10 Gilchrist R. Medieval Life: Archaeology and the Life Course. Woodbridge: Boydell and Brewer; 2012. p. 183.

II Leatherman KD, Dickson RA. The Management of Spinal Deformities. London: Butterworth; 1988. p.6I-2. 
12 Porter R. The Greatest Benefit to Mankind: A Medical History of Humanity from Antiquity to the Present. London: Harper Collins; 1997. p. 51.

13 Moen KY, Nachemson AL. Treatment of scoliosis: an historical perspective. Spine 1999; 24: 2570-75.

14 Armytage WH. The serious Swede: P.H. Ling and his influence on British gymnastics. Practitioner 1956; 177: 200-4.

15 Roth M. The Gymnastic Free Exercises of PH Ling. London: Groombridge and Sons; 1855.

16 Holmberg O. Den Svenska Gymnastikens Utveckling. Per Henrik Ling och hans Verk. Stockholm: Bokfrölaget Naturoch Kultur; 1939.

17 Pembrey MS. Physiological principles of physical training. J $R$ Soc Promot Health I91 I; 32: 345-56.

I8 Karling K. Per Henrik Ling and Swedish medical gymnastics. Physiotherapy 1954; 40: 335-38.

19 Roth B.Treatment of lateral curvature of the spine. Br Med J I882; I: 69I-3.

20 Roth B. Deformed shoulders in young girls. Lancet I88 I; I I8: 107। http://dx.doi.org/ I0.10I6/S0140-6736(02)35591-0

21 Hillman A. Franz Berwald: en biografisk studie. Stockholm:Wahlström \& Nidstrand; 1920.

22 Smith N. Exercises in the treatment of lateral curvature of the spine. Lancet 1900; 156: 13-6.

23 Lewis PG. The Relief and Cure of Spinal Curvatures. London: John Bale Sons \& Danielsson; 1897.

24 Pendell R. A Victory Over Prejudice: The Life and Times of Edward Harrison MD 1759-1838. Horncastle: Bob Pendell; $201 \mathrm{I}$.

25 Weiner M-F, Silver JR. Edward Harrison and the treatment of spinal deformities in the nineteenth century. J $R$ Coll Physicians Edinb 2008; 38: 265-7I
26 Anon. Mechanical Exercise, A Means of Cure: Being a Description of the Zander Institute, London, Its History, Appliances, Scope, and Object. London: J\&A Churchill; I883. p. 5, 47.

27 Fischinger J, Fischinger A, Fischinger D. Doctor Zander's MedicoMechanical Institute in Opatija. Acta Med Hist Adriat 2009; 7: 253 66.

28 Kreck HC, Thomann K-D. ['Restoring health mechanically' Gustaf Jonas Wilhelm Zander's treatment principles]. Z Orthop Ihre Grenzgeb 1987; 125: 593-9. (German)

29 Lau K. Your Plan for Natural Scoliosis Prevention and Treatment. 3rd edn. Singapore: Health in Your Hands; 201 I.

30 den Boer WA, Anderson PG, $v$ Limbeek J et al. Treatment of idiopathic scoliosis with side-shift therapy: an initial comparison with a brace treatment historical cohort. Eur Spine J 1999; 8: 406-10.

3I Weiss H,Weiss G, Petermann F. Incidence of curvature progression in idiopathic scoliosis patients treated with scoliosis in-patient rehabilitation (SIR): an age- and sex-matched controlled study. Pediatr Rehabil 2003; 6: 23-30.

32 Dobosiewicz K, Durmala J, Kotwicki T. Dobosiewicz method: physiotherapy for idiopathic scoliosis. Stud Health Technol Inform 2008; 135: 228-36.

33 Negrini S, Zaina F, Romano $M$ et al. Specific exercises reduce brace prescription in adolescent idiopathic scoliosis: a prospective controlled cohort study with worst-case analysis. J Rehabil Med 2008; 40: 45I-5.

34 Romano M, Minozzi S, Bettany-Saltikov J et al. Exercises for adolescent idiopathic scoliosis. Cochrane Database Syst Rev 2012 ; 8: CD007837. http://dx.doi.org//0.1002//465/858.CD007837. pub2

35 National Institutes of Health. Scoliosis: Causes, Symptoms, Signs, Diagnosis and Treatment. Washington DC: NIH; 2012. 